Ainsworth, G. C. (1955). J. gen. Microbiol, 12, 322-323

\title{
Nomenclature, the Handmaid of Classification
}

\author{
By G. C. AINSWORTH \\ Department of Botany, University College, Exeter
}

\begin{abstract}
'When $I$ use a word', Humpty Dumpty said in rather a scornful tone, 'it means just what I choose it to mean-neither more nor less.'

'The question is', said Alice, 'whether you can make words mean so many different things.'

'The question is', said Humpty Dumpty, 'which is to be Master-that's all.'
\end{abstract}

Lewis Carroll, Through the Looking Glass, 1871.

This intrusion is an attempt to remove a popular misconception; the rather prevalent notion that nomenclature takes precedence over taxonomy, that names in some way determine classification. 'The question is', as Humpty Dumpty once said when discussing semantics with Alice, 'which is to be Master-that's all.' Codes of nomenclature merely regulate the selection and give precision to the use of the names employed after taxonomic decisions have been made and thus prevent the confusion that would result if every taxonomist showed the vigorous individualism of Humpty Dumpty, while at the same time they make it as easy as possible for a taxonomist to use a name so that others can understand just what he chooses it to mean-neither more nor less.

The best use of the short time available is possibly to consider a concrete example and the nomenclature of that well-known micro-organism, the 'thrush fungus', illustrates a number of basic nomenclatural principles and practices.

Since the thrush fungus was first given the Latin binomial Oidium albicans by Charles Robin in $\mathbf{1 8 5 3}$ it has been classified in at least ten other genera, re-described as new at least thirty-six times, and in Lodder and Van Rij's recent monograph (The Yeasts, 1952) ninety-two synonyms are listed after the name of their choice for this fungus. How is the selection of the scientific name for the thrush fungus made? One guiding principle of all international codes of nomenclature is that the correct name of a taxonomic group (or taxon) is the first legitimate one validly published with the same rank. For species this means the combination of a generic name with the earliest available legitimate specific epithet. As far as is known, the first specific epithet to be given to the thrush fungus was albicans, but before the binomial can be completed with a generic name taxonomic decisions must be made. How is this fungus best classified? The genus used by Robin, Oidium, is properly applied to the imperfect states of certain powdery mildews which are unrelated to the yeast-like thrush fungus. For a number of years medical men used the binomial Monilia albicans but the genus Monilia is correctly employed for the imperfect states of the fungi which cause brown rot of fruit. Since 1923 mycologists have favoured the classification of the thrush fungus in the genus 
Candida of Berkhout and the binomial Candida albicans is now familiar. Unfortunately, there were technical objections to Candida as a name because the application of names is given precision by the use of nomenclatural types and there is uncertainty about Berkhout's intentions regarding the type of the genus Candida. Berkhout based her new genus on a fungus which she called C. vulgaris and which she believed to be that described by Bonorden in 1851 as Oidium candidum, but this is open to doubt. She certainly proposed Candida vulgaris as a new species but she may have intended $C$. vulgaris merely as a new name to avoid the illegitimate tautonym $C$. candida. The generic name Candida could, however, be rejected on another score. By including the thrush fungus in the genus Candida, Berkhout included an earlier and overlooked generic name, that of Syringospora, the name given to a genus specially proposed by Quinquand in 1868 for the thrush fungus. Under the Botanical Code, Syringospora takes precedence over Candida and the correct name of the thrush fungus when classified according to Berkhout's views is Syringospora albicans. But the revival of the generic name Syringospora would upset a familiar and widely used name for this common pathogen and so the conservation procedure was invoked and the International Botanical Congress held in Paris in July 1954 agreed that Candida should be conserved against Syringospora and the application of Candida can be clarified by accepting Berkhout's description of her culture as the type of $C$. vulgaris (now considered to be a synonym of C. tropicalis), the nomenclatural type of the genus. C. albicans (Robin) Berkhout is now $a$ correct name under the Code for the thrush fungus. It need not be the only correct name and it need not be the name for all time but it is the name which reflects current taxonomic opinion. How many synonyms there are of C. albicans is again a matter of taxonomic opinion. A taxonomist may at any time consider that Lodder and Van Rij were mistaken in considering a particular species indistinguishable from C. albicans when the species in question would be restored as an independent taxon and its name removed from the synonymy of $C$. albicans.

This example indicates some of the mechanisms of name selection and the moral to be drawn is that good taxonomy is the basic requirement if nomenclatural confusion is to be avoided.

The various international codes of nomenclature are not penal codes. They reflect current usage and they are slowly modified as practice shows them to be inconvenient or to lead to confusion rather than order in the naming of living organisms. The Codes thus grow with the growth of taxonomic practice and attention may be drawn to the fact that the codes have been developed to meet the requirements of classical taxonomy which for larger organisms and for many micro-organisms is firmly based on morphology. For the taxonomy of micro-organisms morphology must frequently be supplemented if not replaced by physiological, biochemical, or serological characters and for the naming of certain taxa defined by such criteria codes of nomenclature as yet offer little guidance. 